\title{
ARTIGOS
}

\section{Em busca de recomposições da prática pedagógica: as narrativas (auto)biográficas de professores(as)}

\author{
Natascha Sokolovicz \\ Regina Cely de Campos Hagemeyer
}

\begin{abstract}
RESUMO:
Este artigo focaliza as percepções dos professores sobre as mudanças contextuais que influenciam os processos pedagógicos na escola contemporânea, das quais decorrem novas necessidades de ensino e formação humana. O estudo foi desenvolvido com base nas teorizações de Costa (2010), Gauthier e Tardif (2010); Hagemeyer (2006; 2014), Nóvoa (2007) e Lévy (1999) e através da metodologia de pesquisa (auto) biográfica, baseada na proposta de formação de Delory-Momberger (2006). A investigação envolveu professores do Ensino Fundamental II, do município de São José dos Pinhais (PR), através de um curso de extensão realizado no Setor de Educação da UFPR. As análises desencadeadas propiciaram a leitura das experiência pessoais e profissionais dos professores, demonstrando tensões, dificuldades e iniciativas, ao acompanhar as mudanças contemporâneas. Evidenciando formas de relacionar-se com o outro, com o mundo e com o conhecimento, recompondo seus saberes e práticas ao constituir-se professores.
\end{abstract}

PALAVRAS-CHAVE:

Prática docente; Pesquisa (Auto) biográfica; Contexto Educacional Contemporâneo;

\section{IN SEARCH OF RENEWALS OF THE EDUCATIONAL PRACTICE THROUGH TEACHERS' (AUTO) BIOGRAPHIC NARRATIVES}

\begin{abstract}
:
This article is focused on the perceptions from teachers in face of the contextual changes regarding the needs of students' education and formation, which influences attitudes and the educational processes they develop. The research regarding the influence of these processes on the constitution of teaching, was made through theorizations of Nóvoa, Costa, Giroux e Hagemeyer and the investigation of teachers' (auto) biographies, based on Delory Momberger's methodology. The research was developed in a course of Extension Program at UFPR, with six teachers of Elementary School II, from São José dos Pinhais (PR) country. The analyses performed enabled the reading of personal and professional experiences from teachers, showing strains, reminiscences and initiatives, by following contemporary changes. Teachers have demonstrated ways to relate with the other, with the world and with knowledge, renewing their understandings and practices by becoming teachers.
\end{abstract}

\section{KEYWORDS:}

Teaching practice; (Auto) biographic research; Contemporary Educational Context; 


\section{autêntica}

\section{INTRODUÇÃO}

A partir da segunda metade do século XX, as instituições educacionais contemporâneas passaram a enfrentar os desafios das rápidas transformações em todas as áreas da vida humana, cujas decorrências nos processos sociais e culturais, interferem nos processos de ensino e formação escolar, desenvolvidos por professores.

No âmago destas mudanças, a evolução da ciência e das tecnologias, tem impulsionado um desenvolvimento sem precedentes na área da comunicação, da informação e do entretenimento, impondo aos professores a ampliação de visões sobre os novos conhecimentos e saberes necessários à própria formação profissional e acerca do tratamento de valores humanos na escola atual.

Objetivando compreender os processos gerados na educação escolar, a partir das transformações contemporaneas, propõe-se detectar as influências científicas, sociais e culturais que interferem na atuação dos professores que atuam no seu âmbito. Esta intenção levou a adotar para a caracterização deste cenário contextual, autores como Borges (2001), Costa (2010), Gauthier e Tardif (2010), Giroux (2003); Hagemeyer (2006; 2014), Nóvoa (2007), Lévy (1999) e Santaella (2003).

Segundo Costa (2010), para além do aperfeiçoamento das máquinas, da técnica e das tecnologias, parece haver uma reestruturação nas formas de interação social, que apontou como uma nova configuração dos processos culturais humanos. Esta nova configuração no entanto, segundo Gauthier e Tardif (2010, p.338), não modificou as formas de exercer a atividade docente de forma substancial, e afirmam os autores que, "para muitos, a escola evoluiu pouco desde o tempo em que era reservada à elite. Suas estruturas rígidas, muitas vezes refratárias à mudança, fazem dela uma instituição do passado". Nesse tempo-espaço de contradições entre a reprodução social e a contestação provocadas por novos processos culturais, os professores se deparam com novas necessidades no trabalho pedagógico, buscando recomposições em sua atuação no âmbito da sala de aula.

Para refletir sobre essa re-composição e/ou re-configuração propõe-se, no presente texto, abordar as percepções dos professores sobre as compreensões e atitudes que os levam a inovar, conservar ou retomar concepções e valores humanos ao desenvolver suas práticas pedagógicas, considerando os processos culturais manifestados pelos estudantes do tempo presente.

Para tanto, optou-se pela utilização de narrativas dos professores sobre os procedimentos e atitudes que adotam em suas trajetórias profissionais, diante de um novo contexto, entrelaçados às suas trajetórias de vida como condutores(as) deste debate. Propõe-se analisar desta forma, como os professores interpretam e traduzem a realidade de sua profissão, num movimento de apropriação dos modelos culturais atuais, e no entrecruzamento com o outro (seus pares, seus alunos, a comunidade escolar), nas formas como atua, diante de novas experiências, atitudes, práticas, ao construir sua profissão como professor.

Para o estudo e as análises sobre os processos de biografização e histórias de vida, propostas nesta investigação, recorreu-se a autores como Josso (2010), Pineau (1988 e 1993), Ferrarotti (1983 e 1988), Delory-Momberger (2003 e 2005), Nóvoa e Finger (1988), e autores brasileiros de referência como Abrahão e Passegi (2012), e Souza (2006), que têm desenvolvido ativa e consistentemente pesquisas nessa área.

A experiência que ofereceu suporte às análises propostas, fundamentaram-se, além dos autores já referidos, inspirou-se metodologicamente nos trabalhos de Crystine Delory-Momberger, e que se refere aos Ateliês 


\section{autêntica}

Biográficos de Projetos (2006), para a proposição de um curso de formação, na modalidade de extensão, desenvolvido no Setor de Educação da Universidade Federal do Paraná. O curso de título: "Narrativas (auto) biográficas - constituindo-se professor", foi ministrado a professores atuantes no Ensino Fundamental II, da rede estadual de São José dos Pinhais, no Paraná.

O eixo central desta pesquisa-formação, norteou-se pela questão apresentada aos professores no último encontro do curso ministrado: Que interferências os professores da escola básica, percebem em suas condu-tas e práticas, em relação à sua geração e à geração atual de estudantes, em seu trabalho como professor? Para a sistematização das análises sobre as respostas obtidas, foram entrecruzadas com as (auto)biografias produzidas nas falas, depoimentos e na escrita dos professores, a partir do processo vivido, aspectos relati-vos às trajetórias de vida pessoal e profissional que interferiram na constituição da profissão docente. Esta questão permeou as atividades do curso proposto desde o início.

Cecília Borges (2001, p. 71) observou o horizonte das pesquisas que envolvem histórias de vida, numa perspectiva na qual o docente é "compreendido com um sujeito portador "de histórias", ou seja, um ser que constrói o mundo em relação com outros sujeitos". Desse modo, as narrativas de vida dos professores são construídas justamente na interação com outras histórias, entremeadas pelos percursos históricos da própria educação escolar e de experiências pessoais e da formação que os levaram a exercer a profissão de professores.

$\mathrm{Na}$ atual conjuntura, a escola torna-se o lugar da diferença e do choque de contextos, de linguagens, de gerações e de grupos sociais e, portanto, um lugar de reflexão constante sobre as necessidades de recom-posição de práticas, diante dos processos culturais gerados por um novo contexto. A sistematização das análises das narrativas e linguagens emitidas nas atividades propostas no curso proposto, comprovaram que a cada fase da aquisição da docência, a consciência sobre as influências e dificuldades do exercício docente, influenciam de forma significativa o próprio desenvolvimento profissional, reiterando a importância da con-tinuidade da realização das pesquisas (auto) biográficas sobre os professores da escola contemporânea.

\section{AS INFLUÊNCIAS DOS PROCESSOS CULTURAIS DO PANORAMA CONTEMPORÂNEO NA CONSTITUIÇÃO PROFISSÃO DOCENTE}

Para compreender as novas necessidades da função docente, considerando as mudanças dos processos culturais contemporâneos, e o seu impacto nas concepções sobre a infância, a adolescência e a juventude dos sujeitos da escola, surgem discussões sobre a necessidade de um despertar o interesse e o desejo desses educandos para a aprendizagem. Essa abordagem foi idealizada historicamente por Rousseau no século XVII, e repercutiu no cotidiano escolar até o século XX e pode ser reconhecida ainda hoje, no século XXI. Nesta perspectiva, ao investigar as práticas e atitudes docentes, parte-se do princípio de que o professor além de perceber as mudanças nas necessidades e interesses dos alunos, passa a buscar novas formas de lidar com questões que se diferenciam das suas convicções e maneiras como aprendeu a se relacionar e ensinar crianças e jovens escolares. Ao modificar formas de ensino diante de situações novas, os professores buscam compartilhar, além do conhecimento disciplinar, o seu olhar sobre o mundo.

Importa no entanto, observar que a imobilidade ainda presente na escola, é confirmada por Xavier (1997, p. 292) que retoma este debate, afirmando: "É fato que a educação está atônita no contexto atual, mas é verdade também que ela nunca teve uma oportunidade tão grande de se transformar e de provocar mudanças nos seus agentes, sejam eles indivíduos ou organizações". 


\section{autêntica}

Pineau (2006, p. 52) traduz as interferências externas e internas às esferas profissional e pessoal dos indivíduos na sociedade pós moderna:

Essa explosão multimidiática pós-moderna e transdisciplinar desenvolve tanto mais o movimento de expressão da vida pelos próprios seres vivos fora da esferas profissionais, científicas e politico-religiosas herdadas quanto a própria vida se problematiza, em todas as suas múltiplas formas de viver, sincronicamente (...) e diacronicamente (...).

No âmbito dessa rede de significações no entanto, as construções dos professores se deparam com as construções de outra rede de significados, a dos alunos. Os autores Green e Bigum (2005, p. 231), procuraram ampliar as compreensões sobre as responsabilidades dos professores diante das diferenças sociais $\mathrm{e}$ culturais no novo cenário educacional:

Discutir adequadamente essas diferenças e responder àquilo que pode ser perfeitamente descrito como uma estrutura pós-moderna de sentimento, exige que aqueles/as de nós que carregamos a responsabilidade de escolarizar o futuro, não apenas desenvolvamos novas compreensões e novos recursos, mas também um sentimento apropriado de humildade, juntamente com o reconhecimento da inevitabilidade da diferença.

A presença exponencial das tecnologias garantiu às novas gerações a imersão neste mundo que propicia a agilidade, a fluidez e o acesso à informação e à comunicação, reduzindo limitações geográficas e temporais, e oportunizando uma configuração social caracteristicamente diferente.

Para Santaella (2003), as utilizações científicas, artísticas e educacionais, as novas profissões e as diversas modalidades de lazer e entretenimento que surgem a partir da cultura digital, passaram a gerar novas formas de registro e síntese da realidade.

Nesta perspectiva, segundo Costa (2010), neste novo panorama cultural, é da interação entre os alunos e as interfaces da cultura digital, que surgem novas formas de perceber e apreender as informações visuais, sonoras, semânticas, de interpretá-las, classificá-las e utilizá-las em situações diversas, gerando novos modos de aprender. $\mathrm{O}$ uso das ferramentas das mídias digitais, assim, demanda o estabelecimento de compreensões sobre sua significação no contexto de socialização e comunicação em que acontecem, proporciona novas formas do ensino e formação valorativa, na interlocução entre aluno e professor.

Segundo Lévy (1999, p.170),

a principal função do professor não pode mais ser uma difusão dos conhecimentos, que agora é feita de forma mais eficaz por outros meios. Sua competência deve deslocar-se no sentido de incentivar a aprendizagem e o pensamento dos alunos.

No âmbito escolar, segundo Hagemeyer (2006), os ritos, a confirmação e repetição de ações ao longo do tempo, as prescrições oficiais e a intensificação das atividades docentes, tendem a ditar ao professor normas, regras, formas de ser e de se movimentar no seu tempo e espaço de trabalho, cerceando muitas vezes a criação do novo, que precisa ser criado.

Quando a escola abre possibilidades e não tolhe o professor, pode-se vislumbrar a criação de novas formas de lidar com a desorganização social, com a evolução científica e tecnológica, com a inovação, com as novas 


\section{autêntica}

linguagens da sociedade digital, refletidas no aluno. A conquista de maior autonomia na construção da docência na escola contemporânea, incide sobre o processo de desenvolvimento profissional de forma significativa.

Belloni (2001) e Hagemeyer (2014), referem-se ao apoio aos professores quanto à possibilidade de maior autonomia e estímulo à expressão de ideias próprias, à sociabilização e ao compartilhamento de experiências que levem à construção aos conhecimentos escolares, como nova qualidade necessária à função docente, que tem como condição, uma maior aproximação aos novos interesses culturais e necessidades formativas dos estudantes da escola contemporânea.

Costa (2010) refere-se a Giroux (2003), o qual aborda a conformação dos cursos de Pedagogia, nos quais necessita-se empreender uma abordagem mais ampla e plurifacetada, que contemple as interfaces entre a educação escolar e a cultura dos sujeitos estudantes, que expressam em seus comportamentos, opiniões e valores, suas inserção nos processos das mídias digitais e suas ordens discursivas.

Hagemeyer (2014), analisou em suas pesquisa que nos processos da cultura escolar, os professores deparam-se com atitudes de maniqueísmo entre o bem e o mal, atitudes de disciplinamento, com julgamentos e san-ções repressoras. De outro lado, os professores verificam que há novas leituras e mobilizações que precisam empreender em suas práticas, para abarcar os significados presentes nas culturas jovens, nas quais circulam novas relações sociais e culturais. Nos defrontamentos que apresentaram em seus depoimentos,comparando com os novos processos culturais contemporâneos, os professores apreendem concepções, procedimentos e atitudes que constituem a profissão docente que apreendem em suas trajetórias.

\section{OS PROCEDIMENTOS METODOLÓGICOS E AS POSSIBILIDADES DE COMPARTILHAR SIGNIFICADOS}

O retorno ao sujeito, nas pesquisas sociais e antropológicas, vem acontecendo desde a década de 1970 e adentra a área educativa com mais vigor, através dos trabalhos com histórias de vida, gradualmente a partir da década de 1980.

Nesse âmbito, cabe demarcar que o objetivo da escrita (auto)biográfica, conforme a definição de Passeggi, Souza e Vicentini (2011, p. 379), "dá aos indivíduos a possibilidade de articular, por meio das narrativas que produzem sobre si, as experiências referências pelas quais passaram, dotando a própria trajetória profissional de sentido". As narrativas de vida são histórias sociais, como define Ferrarotti "[...] se nós somos, se todo indivíduo é, a reapropriação singular ou universal social e histórica que o rodeia, podemos conhecer o social a partir da especificidade irredutível de uma práxis individual (FERRAROTTI, 1988, p. 26-27).

Essa opção metodológica, tornou possível analisar as relações que os professores estabelecem entre o contexto social e cultural mais amplo e as formas de condução no cotidiano escolar, possibilitando a identificação de novas metodologias, experiências pedagógicas e atitudes dos professores, decorrentes das novas necessidades observadas nos alunos.

Nóvoa (2007) conduz à reflexão de que o trabalho educativo, implica na associação do desenvolvimento profissional ao pessoal, e neste sentido, a prática pedagógica cotidiana requer o comprometimento com os valores da profissão docente e o sentido que adquire para o indivíduo que a exerce.

O voltar-se para o sujeito, suas experiências e histórias, nas pesquisas científicas em diversas áreas, incluindo a educação, provocou amplas mudanças metodológicas e conceituais sobre os processos de formação e 


\section{autêntica}

construção da profissionalidade docente. De acordo com Bueno et al. (2006, p. 392), entender o relato de vida como objeto de linguagem e movimento autocriador (produção de si), resultou na adoção dessa prática no campo da formação docente.

Esse processo formativo, originou-se dos trabalhos produzidos na Universidade de Genebra, e aliou em uma mesma perspectiva a formação e a investigação. Segundo Souza (2006, p. 26) esse projeto "configurase como investigação porque se vincula à produção de conhecimentos experienciais dos sujeitos adultos em formação" e simultaneamente, como processo formativo, "parte do princípio de que o sujeito toma consciência de si e de suas aprendizagens experienciais quando vive, simultaneamente, os papéis de ator e investigador da sua própria história".

Para Delory-Momberger (2006) a formação através de (auto)biografias, emana do princípio de que, ao realizar a narrativa de sua vida o indivíduo se apropria de sua própria história.

Essa importância dada à experiência individual está inserida em um movimento global que associa intimamente os formandos aos processos formativos e os considera como os atores responsáveis por sua própria formação (DELORY-MOMBERGER, 2006, p. 361).

A opção pelo dispositivo de formação Ateliê Biográfico de Projeto, proposto por Delory-Momberger, veio a colaborar com uma perspectiva ampliada de formação, na qual objetiva-se trabalhar reflexivamente com as construções narrativas sobre a vida, sendo que o narrador "se constrói como sujeito (individual e social) no ato de sua enunciação" (DELORY-MOMBERGER, 2006, p. 364).

A linguagem, nessa perspectiva, é o espaço onde se produz tanto a história como o sujeito dessa história. Ao narrar-se, o sujeito constrói uma hipótese de si, que será testada pela experiência e reconstruída constantemente. Esse movimento retrospectivo proporciona um olhar perspectivo em relação a futuros possíveis. Surge, então, a dimensão de projeto que sustenta a formação por meio da (auto)biografia, ao estabelecer um encadeamento dialético entre passado e futuro, propiciando, para o sujeito, um espaço de reflexão e emergindo dele a capacidade de mudança (DELORY- MOMBERGER, 2006).

A produção do material de pesquisa neste trabalho, foi obtida por meio da metodologia qualitativa (auto) biográfica através do curso de Extensão Universitária desenvolvido no Setor de Educação, sediado na Universidade Federal do Paraná - UFPR, sob o titulo: Narrativas (auto) biográficas - constituindo-se professor, realizado no ano de 2013, e coordenado pelas autoras do presente artigo. Neste curso foram envolvidos seis professores atuantes em escolas estaduais de Ensino Fundamental II, do município de São José dos Pinhais na Região Metropolitana de Curitiba.

As atividades do curso foram organizadas com intuito de possibilitar a discussão de temas da profissão docente, do compartilhamento de experiências, da construção coletiva de sentidos, utilizando formas de expressão escrita e oral, bem como práticas diversas. Essa produção de materiais, através de atividades mobilizadoras promovidas no curso, proporcionou elementos para o relato e a escrita (auto)biográfica dos professores. A avaliação do processo foi realizada através da aplicação de um questionário semiestruturado e do diálogo sobre a formação vivenciada no curso pelos participantes.

A produção do material de pesquisa neste trabalho, foi obtida por meio da metodologia qualitativa (auto) biográfica através do curso de Extensão Universitária desenvolvido no Setor de Educação, sediado na 
Universidade Federal do Paraná - UFPR, sob o titulo: Narrativas (auto) biográficas - constituindo-se professor, realizado no ano de 2013, e coordenado pelas autoras do presente artigo. Neste curso foram envolvidos seis professores atuantes em escolas estaduais de Ensino Fundamental II, do município de São José dos Pinhais na Região Metropolitana de Curitiba.

A proposta metodológica elaborada por Delory-Momberger (2006), foi organizada no curso proposto, em seis etapas que se desenvolveram de forma progressiva: começando pelo esclarecimento dos procedimentos, objetivos e regras de segurança, e passando para as fases de preparação, negociação e ratificação coletiva do contrato biográfico. A elaboração das narrativas (auto)biográficas e sua socialização, se constituíram o núcleo do trabalho.

No decorrer das fases do curso e das atividades realizadas, os participantes foram instigados a escrever a narrativa (auto) biográfica, fora do ateliê. O processo contou ainda com um período de síntese e construção do projeto pessoal que igualmente é socializado e co-explorado.

As atividades do curso foram organizadas com intuito de possibilitar a discussão de temas da profissão docente, do compartilhamento de experiências, da construção coletiva de sentidos, utilizando formas de expressão escrita e oral, bem como práticas diversas. Essa produção de materiais, através de atividades mobilizadoras promovidas no curso, proporcionou elementos para o relato e a escrita (auto)biográfica dos professores.

Foi organizado ainda, um último encontro destinado à avaliação do processo, que foi realizada através da aplicação de um questionário semi-estruturado e do diálogo sobre a formação vivenciada no curso pelos participantes. Para Delory-Momberger (2006), o trabalho conjunto de elucidação narrativa, auxilia o autor a construir o sentido de sua história e os ouvintes a compreenderem essa história a partir de sua visibilidade exercitada durante o curso.

\section{OS PROFESSORES PARTICIPANTES DA PESQUISA}

Os participantes da pesquisa, compõem um grupo formado por professores que possuíam entre 4 e 22 anos de atuação no magistério e com formação em diferentes áreas. Todos trabalham com ensino Fundamental II. A maioria faz parte do quadro próprio do magistério (Q.P.M.), e apenas um professor estava em regime provisório de trabalho, denominado Processo Seletivo Simplificado (P.S.S.).

TABELA 1- AGENTES DA PESQUISA

\begin{tabular}{c|c|ccc}
\hline Idade & $\begin{array}{c}\text { Tempo de atuação } \\
\text { no magistério }\end{array}$ & Disciplina & $\begin{array}{c}\text { Vínculo } \\
\text { empregatício }\end{array}$ \\
\hline Prof $^{\mathrm{a}}$ Laura & 26 anos & 5 anos & Língua Portuguesa & QPM \\
\hline Profo $^{\circ}$ Gabriel & 26 anos & 4 anos & Ed. Física & QPM \\
\hline Profa $^{\text {Camila }}$ & 28 anos & 9 anos & Matemática & QPM \\
\hline Profa Terezinha & 43 anos & 10 anos & $\begin{array}{c}\text { Língua Portuguesa e } \\
\text { LEM- Inglês }\end{array}$ & QPM \\
\hline Profa Emili & 50 anos & 22 anos & Geografia & QPM \\
\cline { 2 - 5 }
\end{tabular}

Fonte: Elaboração própria 


\section{autêntica}

Segundo Bertaux (2010), os sujeitos da pesquisa passam a ser informantes e a ênfase recai sobre "o que lhes é exterior: os contextos sociais, dos quais eles adquiriram pela experiência, um conhecimento prático." (p. 29). A narrativa torna-se uma forma própria de organizar as experiências docentes, num todo significante e momento de autonomia através da linguagem. Procurou-se desta forma, a construção de uma relação em que, segundo Connely e Clandini (1995), as vozes dos professores e do pesquisador, pudessem ser ouvidas. O posicionamento adotado na pesquisa possibilitou acolher as diferenças como construtivas de um desenvolvimento compartilhado, no qual o professor participante apropria-se de seu papel social e percebe-se enquanto agente histórico que busca espaços de autonomia para criar, modificar e recompor sua prática.

Em discussão com o grupo, optou-se pela utilização de pseudônimos criados por cada professor(a) participante, evitando indicar suas identidades, no decorrer das análises.

\section{ANÁLISE DO PROCESSO VIVIDO: ENTRECRUZANDO OLHARES}

O entrecruzamento de visões e olhares dos professores, apontou diferenças e também semelhanças presentes nesses "mundos", e é nesse contexto da diferenças, que o professor exerce seu trabalho. As noções sobre quem é o professor, os caminhos que percorreu ao constituir-se docente e como se situa na sociedade atual, permeiam seus discursos e sua interação no cotidiano escolar.

Entre os fatores e influências preponderantes destacadas pelo grupo participante da pesquisa, a presença das mídias digitais foi apontada como principal diferença intergeracional vivenciada na relação com os alunos, e que influenciam os interesses e motivações dos estudantes, indicando novas demandas à profissão docente. Considerando estas interferências, inicialmente o professor José emite algumas constatações sobre a profissão docente na sociedade atual:

Hoje se exige um professor muito mais dinâmico do que antes, se exige um professor sempre muito 'hiper' 'mega' atualizado, de maneira que sabe o que o aluno 'curtiu' antes de ir para a aula [...] Por outro lado temos uma sociedade muito superficial. Uma relação humana tão superficial, que entra na área de educação.

Paralelamente à ampliação da utilização das mídias de maneira geral e notadamente as mídias de entretenimento como a televisão, games, etc. e as formas de comunicação proporcionadas pelas redes sociais, os professores apontaram mudanças no comportamento dos alunos. Sinalizaram para a reflexão de que as novas tecnologias não trazem implicações apenas na utilização de recursos durante as aulas, mas numa transformação de atitudes, valores e formas de relacionar-se. Um dos participantes, o professor Gabriel, constatou: "Com certeza a utilização de aparelhos eletrônicos, a mídia digital, influenciam diretamente no planejamento da aula, na execução da didática, na elaboração de trabalhos e avaliações".

Observou-se que a participação ativa deste público de estudantes, ao se comunicar no espaço escolar, têm chamado a atenção do grupo de professores participantes da pesquisa. Em suas reflexões sobre suas histórias, alguns evocaram o lugar que o professor ocupava anteriormente na relação com os educandos. Neste sentido, a professora Terezinha declarou que "O aluno não tinha o direito nem mesmo de se opor às opiniões dos professores, ninguém se atrevia a questioná-lo". Uma vez que o aluno não possuía o direito de voz, o caminho acertado parecia ser o do silenciar-se. 
Com nascimento da Pedagogia Nova no século XX, em confronto com a chamada Pedagogia Tradicional que centrava o ensino na transmissão de conhecimentos, os ideais pedagógicos surgem com força, enfatizando a participação ativa do educando nos processos de aprendizagem e da comunicação. Essas duas concepções estão presentes concomitantemente no cotidiano escolar, como se poderá observar no decorrer das falas dos professores.

A professora Camila relatou que em sua época de estudante "Nós nos conformávamos mais fácil com as coisas". No entanto parece que na época de escolarização desses docentes, havia o início de um movimento de mudança nas relações sociais do espaço escolar. No relato do professor Gabriel, ao se referir sobre seus alunos atualmente, “... as crianças estão mais participativas". Já em sua (auto) biografia revelou: "Sempre fui um aluno participativo, falava demais, e ao final sempre tinha boas notas... Hoje em dia meus alunos são indisciplinados e não tiram notas boas e os que tiram notas boas são aqueles exemplos de disciplina".

Essas colocações remetem a uma tênue linha que separa os movimentos de participação em sala de aula, das atitudes que impedem a aprendizagem. A visão de uma relação frágil entre professores e alunos, aparece também na fala da professora Emili: "Em parte, gosto da participação e dos questionamentos, quando vejo que eles lutam por aquilo que acham justo, mas a liberdade de expressão e os palavrões sem limite me irritam muito”.

A partir de sua própria experiência estudantil, em relação à linguagem e formas de comunicação entre alunos, a professora Laura revelou que "Palavrões e ofensas sempre existiram, mas quando comparo minha época de estudante com a atual, fico chocada com a naturalidade com que se xingam."

Nas analogias estabelecidas entre o passado dos participantes da pesquisa enquanto estudantes, e os alunos com os quais trabalham, as questões sobre disciplina, o comportamento, o respeito para com o professor e seus pares, apareceram de forma recorrente em suas narrativas. Conforme o relato do Professor Gabriel, a relação como aluno com os dirigentes da escola era pautada pelo medo: "Tínhamos até orientadora edu-cacional, e nós temíamos muito sentar no sofá dela, porque a bronca iria ser grande; tinha suspensão e até mesmo expulsão da escola, que hoje isso não é mais permitido". Na mesma direção, a professora Terezinha relata a influência do medo, mesmo antes de entrar no sistema escolar:

Quando criança, a escola me causava pavor, pois a imagem que meus irmãos mais velhos me passavam era que os professores aterrorizavam os alunos com reguadas nas pontas dos dedos, obrigava-os a se ajoelharem sobre grãos de milho segurando livros pesados acima da cabeça, ficavam sem intervalos, e assim por diante. [...] Isso tudo me causou tanto medo que, no dia em que minha mãe me disse que tinha feito minha matrícula para a primeira série, chorei o dia todo de medo de frequentar a escola. Isso não a comoveu, pois meus pais acatavam o que o professor fazia. Ele era respeitado pela comunidade, porém, temido pelos alunos.

$\mathrm{Na}$ fala da professora Terezinha, pode-se perceber que seu contato inicial com a escola se deu entre os anos de 1960 e 1980, período no qual o Brasil contava com um regime político rígido e baseado na autoridade pela força. Da mesma forma as escolas utilizavam castigos físicos e morais para obter o controle e a disciplina. A professora Terezinha lembrou sua época de estudante, ao narrar que:

[...] diferente dos dias atuais, naquela época nem se pensava no ECA (Estatuto da Criança e do Adolescente). Primeiro porque a educação que vinha de casa era muito rígida e o desrespeito aos pais e professores era inadmissível e, segundo, porque o regime que vigorava era o militarismo, ou seja, as regras eram impostas e deviam ser seguidas a qualquer custo, inclusive a força física nas escolas era permitida. 
Pode-se destacar que constituições brasileiras anteriores, já vinham desenvolvendo a ideia de direitos do homem e da criança, que culminaram com o Artigo 206, Constituição Federal atual, que visa garantir entre outros, os direitos referentes à "liberdade de aprender, ensinar, pesquisar e divulgar o pensamento, a arte e o saber", bem como o direito ao "pluralismo de ideias e de concepções pedagógicas, e coexistência de instituições públicas e privadas de ensino" (Constituição Federal de 1988, artigo 206, inciso II e II). Ao final da década de 1980, começam no país movimentos para a construção do Estatuto da Criança e Adolescente (Lei 8.069/1990), que foi aprovada no ano de 1990.

A mutação no sistema de valores humanos, não aconteceu apenas com a promulgação de uma lei, são transformações na forma de pensar e agir que desenvolvem-se lentamente na sociedade e morosamente alcançam a escola. Um novo olhar para a infância vem se construindo desde o início do Século XX, primeiramente com a compreensão da infância e da adolescência como fases distintas e que possuem necessidades específicas, entre elas a proteção, a construção da cidadania e o reconhecimento de direitos e deveres.

A professora Emili também fez referência à autoridade baseada no medo ao afirmar que: "A maioria dos alunos não veem mais os professores com medo. Eles afrontam, discutem, reclamam quando se sentem injustiçados ou não estão interessados na aula, fazem tudo o que podem para atrapalhar". Gauthier e Tardif (2010) já observaram que parece haver relação entre a desestabilização das hierarquias presentes na vida escolar e as múltiplas formas de relação possibilitadas pelas mídias digitais.

Esse novo posicionamento dos educandos, tem levado os professores a buscar caminhos para estabele-cer tipos significativos de interações. Alguns procuram utilizar métodos de seus antigos mestres, como repreensões, posturas mais rígidas, entre outros. Nesse sentido, o professor José revelou não perceber "o menor respeito pela figura do professor, situação que por vezes me faz recorrer a métodos antigos, como por exemplo, o ditado". Alguns professores(as) buscaram ainda, em suas experiências como alunos(as), referências sobre qual seria um comportamento adequado:

Sempre (fui) responsável, ouvia muito e falava pouco, respeitava sempre a professora, não chegava atrasada e não perdia aula. Por isso sou bastante exigente quanto ao comportamento e responsa-bilidade. Era exigido o silêncio quando os professores estavam na sala e, eu faço o mesmo. Tento mudar mas ainda é muito forte esta questão. Professora Emili

O professor Gabriel complementou essa observação dizendo que "...às vezes me vejo como meus alunos de hoje, eufórico, nervoso para a prova, querendo chamar atenção e brigo com eles, como quando meus professores brigavam comigo". No entanto essas táticas de controle utilizadas em épocas passadas, não parecem surtir o efeito desejado.

Buscando compreender as relações construídas e perpetuadas na escola na contemporaneidade a professora Laura relatou perceber que "não há distinção entre professor, aluno ou funcionário." Ao refletir sobre a sociedade atual, Coutinho e Lisboa (2010, p. 12) apontam que "vivemos uma era em que a hierarquia dos modelos tradicionais de conceber o conhecimento, são substituídos pela horizontalidade, em que todos são agentes do processo e, portanto, todos têm vez e voz no sistema de auto-formação".

Intuindo e/ou refletindo sobre isso, alguns professores têm buscado novas formas de relacionar-se com seus alunos para conduzir um trabalho pedagógico relevante. O professor Gabriel descreveu uma situação em que procedeu de forma diferenciada das aplicadas anteriormente o obteve resultados interessantes. 


\section{autêntica}

[...] entrei na turma do $9^{\circ}$ ano $D$, uma turma agitada; conversavam freneticamente e nem notaram o egresso novo professor, e eu meio inseguro não quis erguer o tom de voz ou dar uma bronca; fiz o contrário, entrei no meio da conversa desses jovens adolescentes, e consegui me apresentar e no fundo senti que podia criar um laço de amizade com eles; dito e feito. Me tornei professor representante dessa turma; eles não eram 'fáceis', mais eu sabia como lidar com eles, foi um ano muito gostoso de trabalhar; me senti realizado profissionalmente com as turmas que trabalhei nesse ano.

Ainda que a escola apresente dificuldades à inserção dos novos contextos sociais nos processos de ensino e demonstre, como afirmam Gauthier e Tardif (2010, p.338), “... não ter conseguido construir a ponte entre as transformações tecnológicas e sociais vividas no seio da sociedade e a sala de aula, onde o aluno é "força-do" a estudar, obrigado a escutar, afastado das inovações,...", não se pode negar a força dessas mudanças no pensamento e na prática educativa dos professores.

Buscando recomposições da prática pedagógica a professora Laura, que leciona Língua Portuguesa, explicitou que "muitas vezes, é necessário parar a aula e abordar assuntos de puberdade, sexo, drogas e até palavrões para entender os motivos que os leva a dar tanta importância para esses aspectos." Relatou ainda que:

Como aluna sentia falta de aulas dinâmicas, na época não existia TV pen drive nem acesso a internet e as aulas, em sua grande maioria não eram muito atrativas. Hoje utilizo recursos que atraem a atenção dos alunos mas sem perder o foco no conteúdo programado.

Essa nova forma de interação, que difere muito dos momentos vividos pelos docentes participantes da pesquisa, exige a compreensão crítica das relações entre educação, política e cultura, pois o contraste geracional está interligado às mudanças que vêm permeando a educação e a sociedade nas últimas décadas.

A professora Terezinha lembrou que: "Há uma preocupação quanto à inclusão dos alunos e isso faz com que alunos e professores tenham uma ligação maior." Revelou em suas opiniões, a necessidade de novas maneiras de olhar para o aluno e para as diferenças que se manifestam entre os grupos que frequentam a escola, o que significa desenvolver a docência estabelecendo novas atitudes, relações e práticas pedagógicas.

Ao mudar o foco de sua função, antes centralizada na transmissão de conteúdos, o professor tende a modificar a relação entre o aluno e o conhecimento, como se pôde perceber nos depoimentos a seguir. Para a professora Camila, "Aparentemente a geração atual não tem interesse nos estudos e na minha geração queríamos estudar para ter um futuro melhor... As perguntas referentes ao porquê precisamos aprender a fazer isto ou aquilo, são mais frequentes." A professora Emili, revelou sua insatisfação ao afirmar que: "Hoje me sinto cansada e frustrada ao ver a grande maioria dos alunos totalmente desinteressados, não estudam em casa e muitos levam tudo na brincadeira; pode-se usar a tecnologia etc., mas eles não se interessam".

O professor José apontou como diferença relevante entre sua geração e a geração atual de alunos, a "aptidão para as tecnologias - celulares, tablets, notebooks, etc., o que me faz ter que trabalhar mais com recursos audiovisuais para motivá-los a aprender". No entanto, segundo seu relato, a utilização desses recursos não tem garantido a aprendizagem.

A professora Camila, reiterou essas opiniões ao declarar que, além do ensino dos conteúdos, há necessidade de se estar atento para o uso das ferramentas digitais buscando aprender a utilizá-las para deixar a matéria mais atraente, mais dinâmica. No entanto, segundo a professora, os alunos preferem apenas copiar e colar da Internet. 
O acesso facilitado à informação através da internet, retira da escola seu status de detentora do saber, levando os educadores a refletirem sobre qual seu papel na sociedade atual. Os professores percebem nesse processo de mudança, que a mídia (em geral) e os meios digitais (em particular), vêm desempenhando um papel central na formação e construção de valores culturais contemporâneos de crianças e jovens. Libâneo (1990) instiga o debate sobre essa questão, ao ressaltar o incentivo à aprendizagem, em sua relação com a realidade do educando:

\begin{abstract}
A incentivação como condição de incitamento das forças cognoscitivas dos alunos depende do conhecimento das características individuais e socioculturais dos alunos, pois não ensinamos uma criança "em geral", mas as crianças pertencem a determinadas famílias, e determinada classe social e cuja prática de vida influi na aprendizagem e no desenvolvimento... Porém, essas desvantagens, devem ser o ponto de partida para o trabalho docente, não somente confrontando as experiências de vida e conhecimentos sistematizados, mas incentivando o desejo de melhorar as condições de vida, mostrando a contribuição que a escola pode dar para superar essas desvantagens. (LIBÂNEO, 1990, pp. 113-114)
\end{abstract}

Refletindo sobre os elementos da sociedade atual na aprendizagem, Fabela (2009, p.5) cita de outra perspectiva, a necessidade de experiências significativas, "correspondendo à motivação e necessidade do aprendente e atendendo à sua relação actual com os contextos com que se relaciona" .

As análises expostas até aqui, permitiram perceber que as preocupações dos docentes participantes da pesquisa, não dizem respeito apenas à utilização das mídias digitais em sala de aula, mas às formas de relações que essas constroem entre os indivíduos, a cultura e o saber. Ainda que alguns autores indiquem que há dificuldades de integração das mídias digitais com a prática pedagógica, observa-se um esforço dos professores em utilizar essas ferramentas, percebendo-se estas técnicas como constituintes do rol de conhecimentos e saberes necessários à profissão na atualidade, nos quais figuram novas atitudes e recomposições dos processos de ensino-aprendizagem e formação humana. 


\section{autêntica}

\section{CONSIDERAÇÕES FINAIS}

A pesquisa analisada no presente trabalho, confirmou as contribuições da metodologia (auto)biográfica como uma forma de aproximação ao contexto no qual o olhar do professor adquire um papel fundamental quando problematiza sua própria prática e profissão. Essa abertura para as histórias de vida, a partir do curso desenvolvido, possibilitou compreender como os professores percebem e exercem a docência diante das transformações culturais e sociais contemporâneas.

Ao favorecer o compartilhamento de experiências, num modelo interativo e dialógico, buscou-se a construção de sentidos e significados vividos na docência, possibilitando uma construção coletiva de visões sobre a prática pedagógica nos novos contextos apresentados, resultando num material rico e produtivo para a análise realizada.

Dos relatos dos professores participantes da pesquisa, percebeu-se resquícios da formação e vivência em uma sociedade tradicional, revelando que apesar da evolução nas formas de comunicação e socialização no contexto social atual, e da renovação das propostas curriculares e das práticas pedagógicas, o professor mostrou tensões ou resistências sobre questões relativas às necessárias mudanças de suas práticas, não suficientemente discutidas no meio escolar e entre seus pares.

Essas constatações evidenciaram a necessidade de reflexão mais aprofundada sobre as percepções dos professores sobre a geração atual de alunos, e as influências em suas atitudes, concepções e práticas pedagógicas.

As narrativas dos professores partiram do reconhecimento sobre a relevância do desenvolvimento das mídias digitais e apontaram sua influência na mudança dos processos culturais da sociedade contemporânea, nas relações com o outro, com o mundo e com o conhecimento. A informação atualmente está mais acessível do que em qualquer época histórica anterior. O tempo e o espaço parecem não apresentar mais barreiras à difusão dos conhecimentos.

Essa nova conjuntura contextual, traz para a escola a demanda de acompanhar o processo de instrumentalização dos educandos para agir neste contexto de mudanças científicas e tecnológicas, no qual estão inseridos e não mais no mundo mítico do passado.

Destaca-se, assim, que não são poucos os mal-estares, os conflitos, as dificuldades e tensões que os professores participantes da pesquisa demonstraram experienciar em seu cotidiano profissional. Diante da necessidade de maior familiaridade com as linguagens presentes na sociedade contemporânea, observou-se preocupações dos professores com relação ao domínio e trato dos novos significados veiculados pelas redes sociais, internet e por programações das mídias de entretenimento, com relação aos valores dos estudantes.

É preciso registrar, no entanto, como tornaram evidente em seus depoimentos, que embora os aparatos tecnológicos pareçam representar uma fonte de problemas e dilemas pessoais e profissionais, eles próprios sentem a necessidade de aceitar os vários desafios envolvidos, e que os instiga à recomposição de suas atividades, reconstituindo também o ser professor.

Nessa perspectiva, reitera-se as constatações de Green e Bigun (2005) sobre o sentimento de insegurança dos professores em relação às transformações culturais da contemporaneidade, o que se torna compreensível 


\section{autêntica}

que mobilizem os docentes a enfrentar aa diferenças e diversidades culturais, uma vez que o processo de escolarização significa ensinar para e com a diferença.

Nas comparações de suas trajetórias de vida, com as dos estudantes com que trabalham, professores participantes da pesquisa mostraram as diferenças de atitudes e visões e a necessidade de assumir o papel de mediadores na construção do conhecimento pedagógico e para as aprendizagens dos alunos.

A simples utilização ou manipulação das ferramentas tecnológicas e de meios eletrônicos para os professores, não tem garantido o interesse dos alunos, mas percebeu-se no entanto, a adesão aos novos hábitos digitais dos estudantes. Por outro lado, a percepção sobre o poder dos instrumentos digitais e suas programações, que formam as identidades de crianças e jovens, tem levado os professores a considerar a discussão de problemas sociais diversos, evidenciando preocupações relacionadas com o trato de valores humanos e éticos nos estudantes. Essas disposições têm demandado embasamentos teóricos e práticos sobre os processos e significados das tecnologias e mídias digitais para a escolarização, visando possibilitar uma renovação compreensiva das práticas pedagógicas na docência.

Nos movimentos identificados nas verbalizações e observações das atividades dos participantes da pesquisa--formação, ressalta-se a busca de compreensões sobre as significações dos processos gerados pelas mídias digitais, os percalços para as mudanças de visões e concepções, e a necessidade do apoio e interlocução durante as trajetórias que percorreram na profissão docente.

Respondendo aos processos de mudança científica e tecnológica, percebeu-se um caminhar para modificações das concepções e práticas pedagógicas, que destacaram necessidades com relação ao preparo para uma maior interação dos processos pedagógicos com as mídias digitais, esclarecendo seus significados e potencialidades, notadamente com relação à formação valorativa dos alunos da escola contemporânea.

Cabe salientar que essa pesquisa promoveu um momento ímpar, que se continuado no ambiente escolar e utilizado com abertura para autonomia e discussão aprofundada sobre as mudanças necessárias aos proces-sos da escolarização contemporânea, permearão a construção de novos conhecimentos e saberes sobre, na e para uma constituição qualitativa da profissão docente. 


\section{autêntica}

\section{REFERENCIAS BIBLIOGRÁFICAS}

ABRAHÃO, M. H. M. B., e PASSEGGI, M. C. (org.) Dimensões epistemológicas e metodológicas da pesquisa (auto)biográfica (Tomo I). Natal: EDUFRN; Porto Alegre: EDIPUCRS; Salvador: EDUNEB, 2012.

BELLONI, M.L. O que é mídia e educação. Campinas: Autores Associados, 2001.

BERTAUX, D.Narrativas de vida: a pesquisa e seus métodos. Natal: EDUFRN; São Paulo: Paulus, 2010.

BORGES, C. Saberes docentes: diferentes tipologias e classificações de um campo de pesquisa. Educação \& Sociedade, ano XXII, n 74, pp 59-76, Abril/2001. Web Site: http://www.cedes.unicamp.br/revista/rev/ rev74.html (Acesso em: 20/06/2015).

BRASIL, Constituição da República Federativa do Brasil. Brasília, 1998

Lei Federal n. 8069, de 13 de julho de 1990. ECA _ Estatuto da Criança e do Adolescente.

BUENO, B., CHAMLIAN, H. C., CATANI, D. e SOUSA, C. Histórias de vida e autobiografias na formação de professores e profissão docente (Brasil, 1985-2003). Educação e Pesquisa, 32(2), maio/agosto, pp. 385410, 2006. Web Site: http://www.revistas.usp.br/ep/article/view/28017 (Acesso em: 12/03/2015).

COSTA, M. V. Sobre as contribuições das análises culturais para a formação dos professores do início do século XXI. Educar em Revista, Curitiba, n. 37, p. 129-152, maio/ago., Editora UFPR, 2010. Web Site: http:// ojs.c3sl.ufpr.br/ojs2/index.php /educar/issue/view/979/showToc (Acesso em: 26/06/2015).

COUTINHO, C. e LISBÔA, E. Sociedade da informação, do conhecimento e da aprendizagem: desafios para educação no século XXI. Revista de Educação, Vol. XVIII, nº 1, pp. 5 -22, 2011.

DELORY-MOMBERGER, C. Formação e socialização: os ateliês biográficos de projeto. Educação e Pesquisa, 32(2),pp. 359-371, 2006. Web Site: http://www.revistas.usp.br/ep/article/view/28015 (Acesso em: 26/06/2015).

DELORY-MOMBERGER, C. Fundamentos epistemológicos da pesquisa: biográfica em educação.Educação em Revista, 27(1) abril, pp. 333-346, 2011. Web Site: http://www.scielo.br/scielo.php?pid=S0102-46982011000100015\&script=sci_arttext (Acesso em: 26/06/2015).

DELORY-MOMBERGER, C. Abordagens metodológicas na pesquisa biográfica. Revista Brasileira de Educação, 17(51), dezembro, pp. 523-536, 2012. Web Site: www.scielo.br/pdf/rbedu/v17n51/02.pdf (Acesso em: 26/06/2015).

FABELA, S. A vida toda para Aprender. 2005. In: Portal dos psicólogos. Web Site: http://www.psicologia. com.pt/artigos/textos/A0321.pdf. (Acesso em : 03/03/2014).

FERRAROTTI, F. Sobre a autonomia do método biográfico. In: NÓVOA, A. e FINGER, M. O método (auto) biográfico e a formação. Lisboa: Ministério da Saúde, 1988. p. 17-34. 


\section{autêntica}

GAUTHIER, C. e TARDIF, M. A Pedagogia: teorias e praticas da Antiguidade aos nossos dias. Petrópolis: Editora Vozes, 2010.

GIROUX, H. Atos impuros: A prática política dos estudos culturais. Trad. de Costa Ronaldo. Porto Alegre: Artmed, 2003.

GREEN, B. e BIGUN, C. Alienígenas na sala de aula. In: SILVA, (Org.) Alienígenas na Sala de Aula: uma introdução aos estudos culturais em educação. São Paulo, Vozes, 2005. pp. 203-237.

HAGEMEYER, R.C.C. Formação docente, valores éticos e cultura das mídias digitais: referenciais das práticas de professores para a escola contemporânea. In: MARTINS, Pura Lúcia Oliver e ENS, Romilda Teodora (orgs.). Formação de professores: Interlocução entre universidade e Educação Básica, Revista Diálogo Educacional, Vol. 14, n. 42, Maio/Agosto, 2014.

Função docente e contemporaneidade (Tese de doutorado), Universidade de São Paulo, 2006.

JOSSO, M. C. Experiências de vida e formação (2a ed.). São Paulo: Cortez, 2010.

LÉVY, P. Cibercultura. Rio de Janeiro: Editora 34, 1999.

LIBÂNEO, J. C. Democratização da Escola Pública: A Pedagogia Crítico Social dos Conteúdos. Coleção educar. São Paulo: Loyola, 1994.

NÓVOA, A. Desafios do Trabalho do professor no mundo contemporâneo. São Paulo: SINPRO, 2007.

NÓVOA, A. e FINGER, M. O método (auto)biográfico e a formação. Lisboa: Ministério da Saúde, 1988.

PASSEGGI, M. da C.; SOUZA, E. C. de; VICENTINI, P. P. Entre a vida e a formação: pesquisa (auto)biográfi-ca, docência e profissionalização. Educação em Revista, Belo Horizonte, n.1, vol.27, Apr. p. 369- 386, 2011. Web Site: http://www.scielo.br/scielo.php?script=sci_arttext\&pid=S010246982011000100017 (Acesso em : 13/03/2015).

PINEAU, G. Histórias de vida em formação: gênese de uma corrente de pesquisa-ação-formação existencial. Educação e Pesquisa,32(2), maio/agosto, pp. 329-343, 2006.

Web Site: http://www.revistas.usp.br/ep/article/view/28013 (Acesso em : 26/06/2015).

SANTAELLA, L. Culturas e artes do pós-humano: da cultura das mídias à cibercultura. São Paulo: Paulus, 2003.

SOUZA, E. C. de. A arte de contar e trocar experiências: reflexões teórico-metodológicas sobre história de vida em formação. In.: Revista Educação em Questão. Natal, RN: EDUFRN. V. 25, n. 11, jan./abr., p. 22-39, 2006. Web Site: www.revistaeduquestao.educ.ufrn.br/pdfs/v25n11.pdf (Acesso em: 26/06/2015).

XAVIER, O. S. A Educação no Contexto das Mudanças. Revista Brasileira Est. Pedagógica, Brasília, v. 78 n. 188/189/190. pp. 285-304. Jan./dez. 1997. Web Site: http://rbep.inep.gov.br/index.php/RBEP/article/ view/273/274 (Acesso em: 26/06/2015). 